\section{OP0346-PARE "LISTENING TO PAIN - UN DOLORE DA ASCOLTARE" MULTIDISCIPLINARY SUPPORT FOR WOMEN WITH FIBROMYALGIA}

S. Mingolla, S. Mingolla on behalf of Serena Mingolla Direttore Morfologie author - Francesco Riondino Vice President APMAR Onlus, Ilaria Cinieri Psychologist Cinzia Assalve fibromyalgia Group APMAR Onlus. APMAR, Lecce, Italy

Background: The project "Listening to Pain- un dolore da ascoltare" is a multidisciplinary and multifactorial project addressed to women with Fibromyalgia. Fibromyalgia pain has no boundaries. People describe the pain as deep muscular aching, throbbing, shooting, stabbing, or intense burning. Quite often, the pain and stiffness are worse in the morning, and muscle groups that are used repetitively may hurt more. Pain in every muscle and the profound exhaustion are not symptoms that people can see, but they are real and may be devastating for the person with Fibromyalgia. Although the invisible nature of the condition causes credibility dilemmas for patients.

Objectives: The project aims at improve the quality of life of women with Fibromyalgia. It has the main following objectives: provide information about Fibromyalgia, raise public awareness, collect useful data for research development, give support to the person, reinforcing social networks, provide mediation of the recognition process and bio-energy structured exercise activities and classes tailored to symptoms (stiffness and fatigue) useful in boosting endurance times. Methods: The project was launched in 2015 with a communication campaign and supervised by a group of psychologists promoting the use of humanistic bioenergetics therapy for individual consultations and collective supporting group of discussions. Participants were 50 women with a confirmed diagnosis of FMS. In June 2015, APMAR founded its first "Group for Pathology" and launched new tools as the info point and the toll-free number.

The project includes: psychological support to women suffering from Fibromyalgia, self-help groups where women talk, meet, discuss the pain and jointly organize events and other projects; information, through the creation of brochures and different kind of materials; an info-point managed by APMAR and a toll-free number that provides information and immediate help for women feeling lonely. Results: The psychological and physical well being of women with Fibromyalgia syndrome were enhanced by social support. Chronic Pain, depression, selfefficacy, helplessness, mood disturbance, health status, impact of FMS, were improved. Psychologists involved in the project observe a decrease of depression, greater security and openness in relations. Women started processing and overcoming the sense of loneliness and isolation, increasing knowledge and therefore awareness, acceptance of the disease.

Analyses indicated that the created social support networks were associated with greater levels of self-efficacy for pain and symptom management, higher levels of self-efficacy for function and symptom management, as well as overall psychological well being.

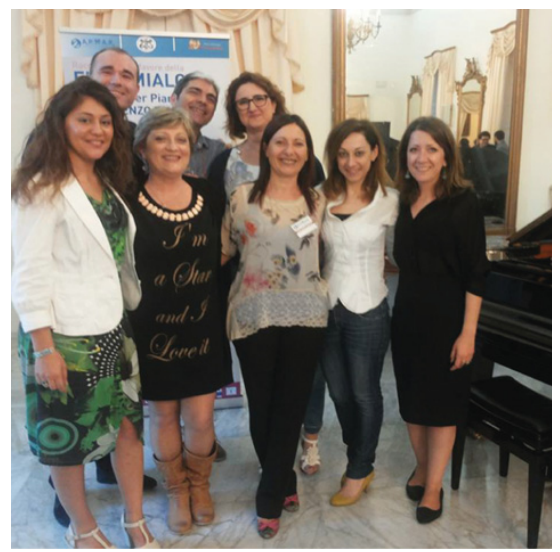

Conclusions: This multilateral approach was very empowering and consented women to work in the same direction to improve healthcare outcomes for people in their same conditions.

Furthermore, it helped women with Fibromyalgia get more control over their life, and promote understanding of patient empowerment. The project was also a call for action not only among patients and health professionals, but among several kinds of social groups of students, press, local policy makers and other civil society organizations

References:

[1] APMAR National Association of People with Rheumatic and Rare Diseases www.apmar.it info@apmar.it.

Disclosure of Interest: None declared

DOI: 10.1136/annrheumdis-2017-eular.2549

SATURDAY, 17 JUNE 2017

\section{Showcasing the EULAR Online Course for Health Professionals}

\section{OP0347-HPR TRAINING RHEUMATOLOGY NURSE SPECIALISTS: WHAT DOES THE FUTURE HOLD?}

M.K. Nisar ${ }^{1}$, J. Begum ${ }^{2} .{ }^{1}$ Rheumatology, Luton \& Dunstable University Hospital; ${ }^{2}$ Rheumatology, Luton, Luton, United Kingdom

Background: Since the introduction of the Rheumatology nursing in the UK in 1980s, there has been gradual development of the "specialty". Despite the proven benefits, both clinical and economical, of a well-trained rheumatology nurse specialist and the evolution of the role, there is a lack of a clear career path for the profession.

Objectives: We undertook a pilot survey to understand the present climate of rheumatology practitioner training in the region.

Methods: Following a focus group discussion of an "ideal" development route for rheumatology practitioners, ten items were unanimously identified as areas for job progression. These included appropriate induction, prescribing skills, involvement in research and education, opportunities for combined working and scope for clinical development. A questionnaire was created based on these items and mailed to all the rheumatology units in the East of England. Replies were compiled to ascertain the current picture of regional training.

Results: There are 19 centres providing rheumatology services in the region with 51 rheumatology practitioners. All of them (100\%) replied to the questionnaire. Only four units $(21 \%)$ provide formal induction programme for training. 11/19 $(57 \%)$ have nurse prescribers. All providers replied positive to the question pertaining nurses' participation in research and audit; $12(63 \%)$ have presented locally or nationally and eight (42\%) have submitted posters to conferences. 12 centres have partly nurse delivered early arthritis pathway and 13 have access to departmental ultrasound. Ten units provide patient educational events.

Conclusions: This is a pioneering survey outlining access of rheumatology practitioners and nurse specialists to developmental opportunities. This initiative highlights a wide variation in the provision of clear career pathway regionally. Though most centres are delivering contemporary services, these are not being used effectively for developing key team members. There is lack of formal induction programme. Though most nurses are involved in audit, less than a quarter are presenting at any level and even fewer are publishing research endeavours. Prescribing is limited to $15 / 51$ (29\%) members. Less than $20 \%$ are training to do intra-articular injections or learning musculoskeletal ultrasound. Despite patient education being a core skill for this group, only 10 units deliver these as a formal event.

In conculsion, there is wide variation in the provision of career advancing opportunities to rheumatology nurse specialists. This can potentially have a negative impact on staff recruitment and retention. There is a need for improving standards and delivery of rheumatology professionals' career development.

Disclosure of Interest: None declared

DOI: 10.1136/annrheumdis-2017-eular.2786 